\title{
Assessment by cross sectional echocardiography of surgical "mitral valve" disease in children and adolescents
}

\author{
EDGARDO ORTIZ, JANE SOMERVILLE \\ From the Paediatric and Adolescent Unit, National Heart Hospital, London
}

SUMMARY The anatomy of the left atrioventricular valve, a mitral valve unless there is atrioventricular discordance, was determined by cross sectional echocardiography in 15 young patients with congenital lesions and seven with rheumatic lesions. These results were compared with findings at operation. The preoperative diagnosis was accurate in $18(80 \%)$. In the remaining four patients inaccurate echocardiographic diagnosis was due to the mistaken identification of clefts in redundant and multicuspid valves and of absent chordae that were thought to be ruptured chordae. In four patients a subvalvar abnormality was identified by echocardiography.

With care, cross sectional echocardiography was a reliable method of defining abnormal anatomy in serious mitral disease and it predicted the need for replacement or the possibility of repair. In the absence of additional lesions invasive investigation was unnecessary.

The appropriate management of young patients with left atrioventricular valve disease that is severe enough to require surgical treatment is assisted by a knowledge of the anatomical abnormalities before operation. With some lesions mitral valve replacement is inevitable. With others, however, mitral valve repair will achieve good haemodynamic results. The severity and cause of the lesion are not difficult to assess but with invasive investigation it is difficult to define the anatomy of the lesion before operation.

Echocardiography has provided valuable information on the anatomy of the abnormal left atrioventricular valve. ${ }^{1}$ The $M$ mode is useful in detecting mitral stenosis but is of little use in defining the anatomy ${ }^{2}$ except in occasional lesions. Cross sectional echocardiography allows better definition of the cusps, subvalvar apparatus, and valve mobility. ${ }^{3}$

We prospectively determined the accuracy and reliability of cross sectional echocardiography in assessing the anatomy of surgically important

Requests for reprints to Dr Jane Somerville, Paediatric and Adolescent Unit, National Heart Hospital, Westmoreland Street, London W1M 8BA.

Accepted for publication 15 April 1986 lesions of the left sided atrioventricular valve in young patients and in defining those lesions that are likely to be suitable for repair.

\section{Patients and methods}

The criteria for inclusion in the study were (a) presence of left atrioventricular valve disease severe enough to need operation in patients aged $<25$ years; (b) echocardiographic investigation in which a good window and recording were achieved; and (c) confirmation of valve anatomy by open inspection at operation. We excluded patients with atrioventricular septal defects having their first operation, because such patients have been considered elsewhere ${ }^{45}$ and their anatomy is well established.

Twenty two patients were studied (12 males and 10 females). The mean age was 8.9 years $(2-22$ years; three were aged $<5$ years). In seven the aetiology of the valve abnormality was rheumatic and in 15 it was congenital (table).

Real time cross sectional echocardiography was obtained with an ATL mechanical sector scanner and 3.5 and $5 \mathrm{MHz}$ transducers. The studies were recorded on a U-matic videotape recorder with the patient supine and from standard views. ${ }^{6}$ We focused our attention on the left atrioventricular 
Table Clinical and echocardiographic data on 22 patients with surgically treated mitral valve disease

\begin{tabular}{|c|c|c|c|c|c|c|c|}
\hline $\begin{array}{l}\text { Case } \\
\text { No }\end{array}$ & $\begin{array}{l}\text { Age } \\
(y r)\end{array}$ & Sex & Added lesions & $\begin{array}{l}\text { Aet } \\
M V\end{array}$ & Abnormality predicted by echo & Errors & Operation result \\
\hline $\begin{array}{l}1 \\
2 \\
3 \\
4 \\
5\end{array}$ & $\begin{array}{r}7 \\
22 \\
12 \\
7 \\
3\end{array}$ & $\begin{array}{l}\mathbf{F} \\
\mathbf{M} \\
\mathbf{M} \\
\mathbf{F} \\
\mathbf{M}\end{array}$ & $\begin{array}{l}\text { DA } \\
\text { ASD } \\
\text { VSD (muscular) } \\
\text { Aortic coarctation, DA }\end{array}$ & $\begin{array}{l}\mathbf{C} \\
\mathbf{R} \\
\mathbf{C} \\
\mathbf{C} \\
\mathbf{C}\end{array}$ & $\begin{array}{l}\text { Dyplastic (both cusps) } \\
\text { Mitral stenosis } \\
\text { AL prolapse, } \mathrm{PL} \text { normal, } \mathrm{AD} \\
\text { AL prolapse and cleft, } \mathrm{PL} \text { hypo, } \mathrm{AD} \\
\text { Dysplastic, } \mathrm{AL} \text { prolapse and cleft, } \mathrm{AD}\end{array}$ & $\begin{array}{l}\text { No cleft } \\
\text { No cleft }\end{array}$ & $\begin{array}{l}\text { Replacement } \\
\text { Commissurotomy } \\
\text { Repair } \\
\text { Replacement } \\
\text { Failed repair, } \\
\text { replacement }\end{array}$ \\
\hline $\begin{array}{r}6 \\
7 \\
8 \\
9 \\
10 \\
11 \\
11 \\
12 \\
13\end{array}$ & $\begin{array}{r}6 \\
8 \\
7 \\
15 \\
11 \\
12 \\
9 \\
5\end{array}$ & $\begin{array}{l}F \\
F \\
F \\
M \\
M \\
M \\
F \\
M\end{array}$ & $\begin{array}{l}\text { AR, prolapse NCC } \\
\text { ASD }\end{array}$ & $\begin{array}{l}\mathbf{C} \\
\mathbf{R} \\
\mathbf{C} \\
\mathbf{R} \\
\mathrm{R} \\
\mathrm{R} \\
\mathrm{C} \\
\mathrm{C}\end{array}$ & $\begin{array}{l}\text { AL prolapse, } \mathrm{PL} \text { ret, } \mathrm{AD} \\
\text { Chordae short, ret, leaflets ret } \\
\text { AL prolapse, PL ret, } \mathrm{AD} \\
\text { AL prolapse, PL ret } \\
\text { AL prolapse, PL ret, thick } \\
\text { AL prolapse, PL ret } \\
\text { AL and PL prolapse } \\
\text { Chordae ruptured AL, AD }\end{array}$ & Absent chordae & $\begin{array}{l}\text { Replacement } \\
\text { Replacement } \\
\text { Repair } \\
\text { Replacement } \\
\text { Repair } \\
\text { Replacement } \\
\text { Replacement } \\
\text { Failed repair, }\end{array}$ \\
\hline 14 & 2 & $\mathbf{F}$ & $\underset{\text { PA }}{\text { Anomalous LCA from }}$ & C & $\begin{array}{l}\text { Papillary muscles calcified, }{ }_{\text {AD }} \text { fibrosed, } \\
\text {. }\end{array}$ & & Replacement \\
\hline 15 & 6 & $\mathbf{M}$ & Aortic coarctation, DA & C & AL prolapse and cleft, PL normal & & $\begin{array}{l}\text { Failed repair, } \\
\text { replacement }\end{array}$ \\
\hline $\begin{array}{l}16 \\
17\end{array}$ & $\begin{array}{r}2 \\
15\end{array}$ & $\begin{array}{l}\mathbf{M} \\
\mathbf{F}\end{array}$ & $\begin{array}{l}\text { VSD (subaortic) } \\
\text { Corrected TGA, VSD, } \\
\text { PS }\end{array}$ & $\stackrel{\mathrm{C}}{\mathrm{C}}$ & $\begin{array}{l}\text { Dysplastic (both cusps), anterior cleft } \\
\text { Dysplastic, Ebstein's malformation }\end{array}$ & Pentacuspid & $\begin{array}{l}\text { Repair } \\
\text { Replacement }\end{array}$ \\
\hline 18 & 7 & $\mathbf{F}$ & & $\mathbf{R}$ & $\begin{array}{l}\text { Chordae ruptured, AL prolapse } \\
\text { and PL normal }\end{array}$ & & Replacement \\
\hline $\begin{array}{l}19 \\
20 \\
21\end{array}$ & $\begin{array}{r}4 \\
12 \\
15\end{array}$ & $\begin{array}{l}\mathbf{M} \\
\mathbf{M}\end{array}$ & $\begin{array}{l}\text { AVS (bicuspid) } \\
\text { Aortic coarctation, DA }\end{array}$ & $\begin{array}{l}\mathbf{C} \\
\mathbf{R} \\
\mathbf{C}\end{array}$ & $\begin{array}{l}\text { Dysplastic (both cusps) } \\
\text { AL prolapse, PL ret } \\
\text { Dysplastic (both cusps), AD }\end{array}$ & & $\begin{array}{l}\text { Replacement } \\
\text { Repair } \\
\text { Failed repair, } \\
\text { replacement }\end{array}$ \\
\hline 22 & 8 & $\mathbf{M}$ & Primum ASD & C & Double orifice mitral valve (S) & & Repair \\
\hline
\end{tabular}

$A D$, annular dilatation; Aet MV, aetiology of the mitral valve disease; $A L$, anterior leaflet; AR, aortic regurgitation; $A S D$, atrial septal defect; AVS, aortic valve stenosis; C, congenital; DA, ductus arteriosus; hypo, hypoplastic; LCA, left coronary artery; NCC, non-coronary cusp; PA, pulmonary artery; PL, posterior leaflet; PS, pulmonary stenosis; R, rheumatic; ret, retracted; (S), surgically induced; TGA, transposition of the great arteries; VSD, ventricular septal defect; *acquired.

valve apparatus in the parasternal long axis view, and by sweeping from the apex of the left ventricle to the outflow tract in the parasternal short axis view we assessed the valvar and subvalvar regions. A subxiphoid four chamber view was used to display the papillary muscles and chordae. The annular size was evaluated in the parasternal long axis projection as previously described. ${ }^{?}$

Prolapse has been defined as motion of the anterior and posterior leaflet producing bellying of the valve more than $2 \mathrm{~mm}$ above the atrioventricular groove in long axis and apical four chamber views. Unless they were in flailed valves the cusps were described as dysplastic when they were thick, lumpy, and with restricted mobility. Other descriptions are self explanatory.

Only six of the 22 patients had preoperative cardiac catheterisation with left ventricular angiography after echocardiography. Catheterisation was performed to assess additional lesions.

All patients had open heart surgery. The mitral valve was repaired in seven and replaced in 15; four of these had early reoperation after a failed repair.

The table compares the results of the cross sectional echocardiography with the findings at operation.

\section{Results}

ABNORMAL ANATOMY OF THE MITRAL VALVE The mitral valve dysfunction was generally caused by abnormalities of either the leaflets or subvalvar apparatus.

In 17 patients leaflet abnormality was identified as the prime cause of mitral regurgitation. Ten of these patients had minor abnormalities in the subvalvar apparatus and a further four had major abnormalities of the chordae or papillary muscles or both and one (case 2) had rheumatic mitral stenosis. There was prolapse of one or both leaflets in 11 of the 17 with primary leaflet abnormality and one of them (case 5) had thick dysplastic cusps with prolapse of the anterior leaflet because of annular dilatation. A further five had dysplastic leaflets which did not coapt or prolapse and one (case 22) had surgically created double orifice mitral valve after repair of an ostium primum defect.

In 10 patients the anterior leaflet alone was prolapsed (fig 1) and in one (case 12) both cusps were affected. In six of those with prolapsed anterior cusps the posterior leaflet was retracted, in two it was normal, and in the other two it was hypoplastic. Four of the six cases of prolapsed anterior leaflet and 

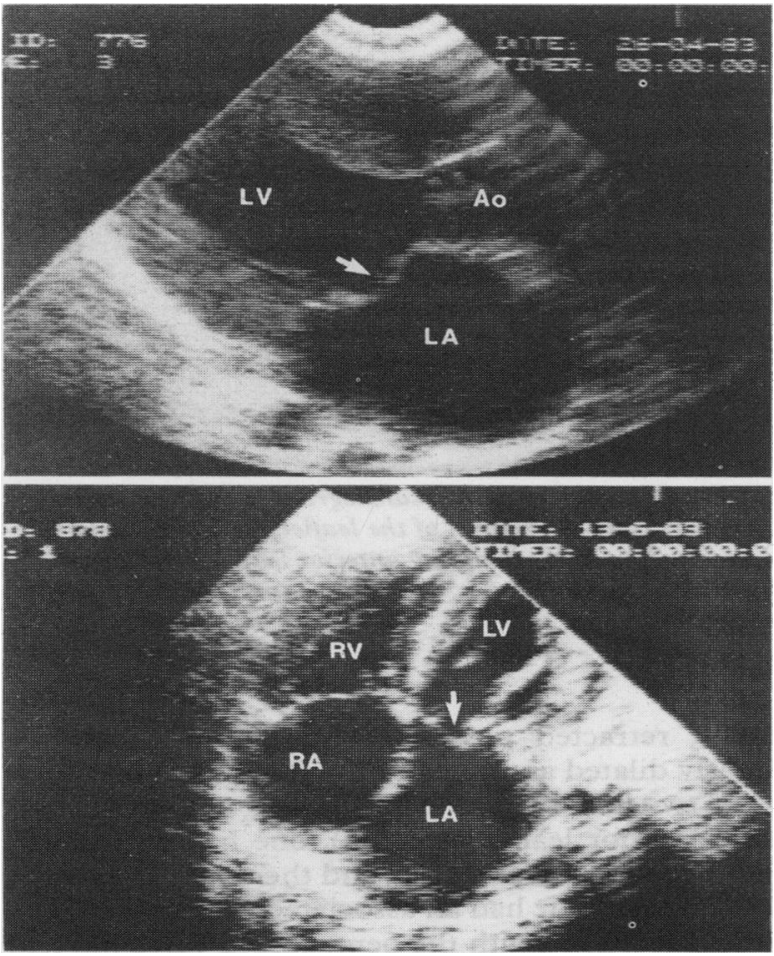

Fig 1 (Top) Cross sectional echocardiogram in the parasternal long axis view at left sternal border from case 8 with atrial septal defect, showing bowing of the anterior leaflet $>2 \mathrm{~mm}$ above the atrioventricular groove (arrow) during systole. The posterior leaflet looks normal. A dilated annulus was also seen in this view. (Bottom) Cross sectional echocardiogram in the apical four chamber view in case 9 with rheumatic disease, showing the anterior leaflet (arrow) prolapsing into the left atrium during ventricular systole. The chordae are thick. Ao, aorta; $L A$, left atrium; $L V$, left ventricle; $R A$, right atrium; $R V$, right ventricle.

retracted posterior leaflet had a rheumatic aetiology and in the other two there were associated congenital lesions (secundum atrial septal defect (case 8) and aortic regurgitation from thin and floppy noncoronary cusp (case 6)). The other four cases of anterior leaflet prolapse and normal or small posterior leaflet also had other congenital lesions-secundum atrial septal defect (case 3), coarctation (cases 5 and 15), and ventricular septal defect (case 4). In case 15 there was a true cleft in the redundant cusp. The patient (case 12) in whom both cusps were prolapsed had an atrial septal defect.

Five of six patients with dysplastic valves (fig 2) had minor abnormalities in the subvalvar apparatus such as thickening or elongation of the chordae. In the remaining patient (case 17) with "corrected

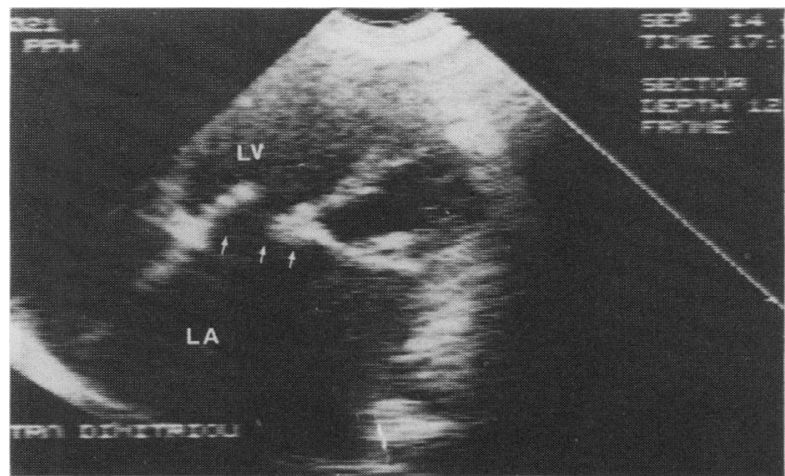

Fig 2 Cross sectional echocardiogram in the apical four chamber view in case 1, showing the thick, lumpy, dysplastic cusps (arrows) that move little during diastole. The left atrium is enlarged and the patient had a duct, which is not seen in this view. $L A$, left atrium; $L V$, left ventricle.

transposition"' and an Ebstein's malformation of the left atrioventricular valve with short chordae the leaflet attached near the apex of the left ventricle. In two patients annular dilatation (cases 5 and 21) contributed to the regurgitation and one of them (case 5) had a prolapsed anterior leaflet and unusual mobility. The table shows the other anomalies that were often found in patients with dysplastic mitral valves.

Four patients had major subvalvar abnormalities. One (case 18, fig 3 ) had ruptured chordae and another (case 7) had thick retracted chordae; in both cases the cause was rheumatic. In case 13 absent chordae caused serious mitral regurgitation. In the patient (case 14) with anomalous left coronary artery arising from the pulmonary artery, calcification of the anterior papillary muscle and

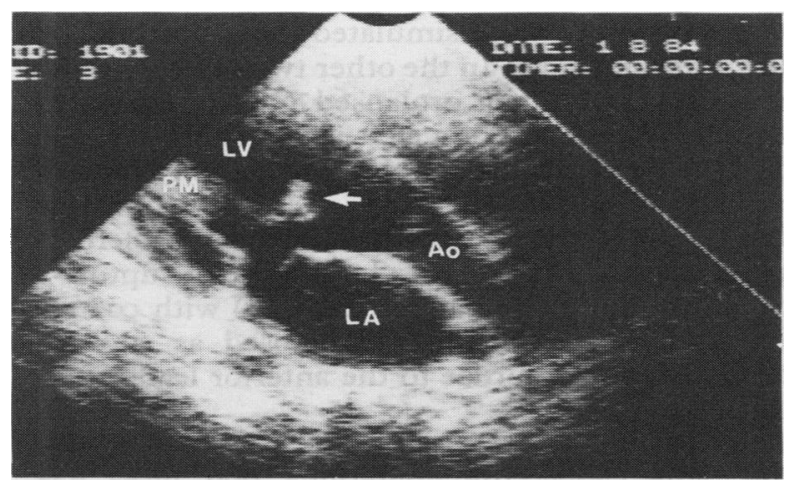

Fig 3 Cross sectional echocardiogram in the apical two chamber view in case 18 with rheumatic mitral disease, showing remnants of the chordae (arrow) attached to the papillary muscle. Ao, aorta; $L A$, left atrium; $L V$, left ventricle; PM, papillary muscle. 
chordae (fig 4) anchored the anterior cusp and caused mitral regurgitation. This patient presented as a case of cardiomyopathy.

The clean fish mouth appearance of the normal mitral valve orifice was not seen in the short axis view in any patient. All had abnormal coaptation and asymmetric opening and closing movements of the leaflets.

\section{ECHOCARDIOGRAPHIC PREDICTION OF ABNORMALITY}

The table shows the abnormalities predicted by cross sectional echocardiography. In $18(80 \%)$ patients the diagnosis was correct. In four the preoperative diagnosis was wrong; three were mistakenly thought to have cleft anterior leaflets and one was diagnosed as having ruptured chordae. In case 16 a pentacuspid valve simulated the appearance of a cleft anterior leaflet. In the other two cases there was an unusual redundant prolapsed anterior leaflet that gave the impression of a cleft in the short axis view (fig 5). The pentacuspid valve was initially repaired but regurgitation persisted. Repeat echocardiography suggested the reappearance of a cleft. At operation this was found to be the site of rupture of the suture line. The patient (case 13) with coarctation that was erroneously diagnosed as ruptured chordae had no chordae to the anterior leaflet.

\section{SURGERY}

The table shows the operations that were performed. Valve repair was initially performed in 10 patients; it failed in four of them. It was successful in one patient with mitral stenosis and five with mitral regurgitation associated with a prolapsed anterior

leaflet, retracted posterior leaflet, and normal or slightly dilated annulus. Of the four in whom repair failed two had dysplastic valves (one with a concomitant anterior leaflet prolapse), one had an isolated anterior cleft and prolapse, and the other had absent chordae. All four had an associated coarctation. The patient (case 16) with the pentacuspid valve has had two repairs but regurgitation has remained severe and the valve will be replaced.

Valve replacement was performed as the first procedure in 11 patients-six with dysplastic valve cusps, three with severe subvalvar lesions (short, retracted chordae, ruptured chordae, absent chordae, and calcified papillary muscles and chordae), and two with a combination of prolapsed anterior leaflets and hypoplastic posterior leaflet but with severe annular dilatation and elongated chordae.

\section{Discussion}

We studied only patients with mitral disease that was severe enough to require surgical treatment and we cannot comment on the accuracy of cross sectional echocardiography in recognising less severe abnormalities of the mitral valve.

Cross sectional echocardiography is better than angiography for viewing valve motion, morphology, and the anatomy of the valvar and subvalvar apparatus in several planes. Thus it gives precise information on all parts of the mitral valve. In this series the examination reliably recognised prolapse of the mitral valve leaflets, dysplastic, lumpy valves, retracted and hypoplastic posterior leaflets, annular dilatation, and abnormalities of the chordae and papillary muscles, such as rupture, retraction, and 
calcification. Single papillary muscle, parachute valves, ${ }^{7}$ and double orifice valves ${ }^{8}$ are also recognisable.

The major error was in overdiagnosis of cleft anterior leaflet. Criteria for diagnosis of isolated clefts were proposed by Smallhorn et al, ${ }^{4}$ but we believe that there are various sources of error. Several abnormalities, such as the fold of a redundant prolapsing anterior leaflet, seen when in the short axis view from the aortic root to apex of the left ventricle, can mimick the appearance of a cleft pointing towards the left ventricular outflow tract (fig 5). Abnormal leaflet septations such as those that are seen in pentacuspid valves can also present as clefts. A curious mitral valve abnormality in which the anterior leaflet is small and the posterior leaflet is long and narrow was not seen in this series. The unusual site of the commissure may simulate a cleft ( $M$ de Leval, personal communication) and such patients may be referred for a premature or unnecessary valve replacement.

Mistakes in assessment of subvalvar problems were uncommon. Free floating flail leaflets were attributed to ruptured chordae when in fact chordae were absent. It may be difficult to identify the stub of the chordae if the cusp edge is curled, and in young patients with congenital lesions identification of such a stub may be impossible.

Six patients in this series had invasive investigation because of the associated lesions. This did not contribute further knowledge of the mitral valve anatomy. Currently invasive investigation of mitral valve disease is performed in young patients to assess its severity in the presence of other cardiac lesions.

Because of the difficulties associated with prosthetic valves, ${ }^{9}$ the decision to replace mitral valves in children should be carefully considered. In this study the echocardiographic appearance of the diseased mitral valve allowed us to assess whether repair was possible or to say that replacement was inevitable. Surgeons differ in their approach to repair of the mitral valve. But predictions about the need for repair or replacement were confirmed in $90 \%$ of patients treated by a surgeon who took note of the preoperative echocardiographic results. Valve repair is possible when the main abnormality is anterior leaflet prolapse associated with annular dilatation, particularly in patients with rheumatic disease; when the posterior leaflet is retracted and not accompanied by severe annular dilatation; when there are no associated major subvalvar abnormalities such as ruptured chordae; in rheumatic mitral stenosis; and when there are isolated clefts of the anterior leaflet of normal valves. This last condition was not encountered in this prospective study; the only patient with a cleft had an unusual redundant anterior leaflet that prevented the repair.

Valve replacement is probably inevitable when valves are dysplastic and are causing serious haemodynamic disorder, in the presence of ruptured or absent chordae, and when serious papillary muscle disease is causing chordal shortening. We accept that there is considerable variation in the surgical management of mitral valve disease and that others may succeed in repairing some of these lesions. ${ }^{10}$

Cross sectional echocardiography is a reliable method of assessing the anatomy of important mitral valve disease. When this technique is coupled with clinical assessment and other non-invasive investigations, patients may be sent for surgery without cardiac catheterisation and angiography. Cross sectional echocardiography helps to predict the possibility of repair or the need for replacement and thus may influence the timing of operation.

We thank our surgical colleagues, Mr Marc de Leval, Mr Magdi Yacoub, and Mr Donald Ross for checking our echocardiographic findings with the surgical specimens and for their patience in explaining the anatomy and their tolerance of our mistakes.

E $O$ is a Squibb Medical Systems Research Fellow.

\section{References}

1 Schwartz DC, Kaplan S, Meyer RA. Mitral valve prolapse in children: clinical, echocardiographic and angiographic findings in 81 cases [Abstract]. Am $\mathcal{F}$ Cardiol 1975;35:169.

2 Nichol PM, Gilbert BW, Kisslo JA. Two dimensional echocardiographic assessment of mitral stenosis. Circulation 1977;55:120-8.

3 Sahn DJ, Wood J, Allen HD, Peoples W, Goldberg SJ. Echocardiographic spectrum of mitral valve motion in children with and without mitral valve prolapse: the nature of false positive diagnosis. Am $\mathcal{F}$ Cardiol 1977;39:422-31.

4 Smallhorn JF, de Leval M, Stark J, et al. Isolated anterior mitral cleft. Two dimensional echocardiographic assessment and differentiation from "clefts" associated with atrioventricular septal defect. Br Heart $\mathcal{F}$ 1982;48:109-16.

5 Smallhorn JF, Tommasini G, Anderson RH, Macartney FJ. Assessment of atrioventricular septal defects by two dimensional echocardiography. Br Heart f 1982;47:109-21.

6 Tajik AJ, Seward JB, Hagler DJ, Mair DD, Lie JT. Two dimensional real time ultrasonic imaging of the heart and great vessels. Mayo Clin Proc 1978;53:271-303.

7 Smallhorn J, Tommasini G, Deanfield J, Douglas J, Gibson D, Macartney F. Congenital mitral stenosis. Anatomical and functional assessment by echocardiography. $\mathrm{Br}$ Heart $\mathcal{f}$ 1981;45:527-34.

8 Warnes C, Somerville J. Double mitral valve orifice in atrioventricular defects. Br Heart f 1983;49:59-64.

9 Berry BE, Ritter DG, Wallace RB, McGoon DC, Danielson GK. Cardiac valve replacement in children. $f$ Thorac Cardiovasc Surg 1974;68:705-10.

10 Carpentier A, Branchini B, Cour JC, et al. Congenital malformations of the mitral valve in children. Pathology and surgical treatment. I Thorac Cardiovasc Surg 1976; 72:854-66. 